\title{
Numerical Analysis of Transport Phenomenon Inside a Pulse Tube Refrigerator Coupled with Fuzzy Logic Controller
}

\author{
S.K. Rout ${ }^{1}$, Ahmed Kadhim Hussein ${ }^{2, *}$, R.K. Sahoo ${ }^{1}$, S.K. Sarangi ${ }^{1}$, M. Hasanuzzaman ${ }^{3}$ \\ ${ }^{1}$ Department of Mechanical Engineering,NIT Rourkela-769008,Odisha,India \\ ${ }^{2}$ Mechanical Engineering Department, College of Engineering, Babylon University, Babylon City, Iraq \\ ${ }^{3}$ UM Power Energy Dedicated Advanced Centre (UMPEDAC), Level 4, Wisma R\&D, University of \\ Malaya, 59990 Kuala Lumpur, Malaysia \\ *Corresponding Author: ahmedkadhim7474@gmail.com
}

Copyright (c) 2013 Horizon Research Publishing All rights reserved.

\begin{abstract}
This research article illustrates a numerical study of single stage coaxial as well as inline Inertance-Type Pulse Tube Refrigerator (ITPTR). In this present work a computational fluid dynamic (CFD) approach has been adopted for numerical simulation purpose. The detail analysis of cool down behaviour, heat transfer at the cold end and the pressure variation inside the whole system has been carried out by using the most powerful computational fluid dynamic software package FLUENT. A number of cases have been solved by changing the porosity of the regenerator from 0.5 to 0.9 while the rest of the considered parameter are remains unchanged. The operating frequency for all the studied cases is $(34 \mathrm{~Hz})$ while the other system dimensions and the boundary conditions are considered unchanged for all cases. The results show that the porosity value of (0.6) produces a better cooling effect on the cold end of the pulse tube refrigerator. The variation of the pressure inside the pulse tube refrigerator during the process are also analysed. In this work an attempt has been made to make a thermally non-equilibrium model applied numerically to the porous region by considering two different energy equations to the solid matrix and for the fluid inside the porous medium and the results are compared with the thermally equilibrium model. In fact, to get an optimum parameter experimentally is a very tedious for iterance pulse tube refrigerator job, so that the CFD approach gives a better solution which is the main purpose of the present work. In the next part the fuzzy logic approach is applied to optimize the different component parameters that affect the cooling performance of the ITPTR. The investigation is performed with different design parameters such as the length and diameter of pulse tube and regenerator given as an input to the fuzzy controller while the output from the controller is the cold end temperature. The predicted optimum results have been verified by performing the confirmation tests.
\end{abstract}

Keywords Pulse Tube Refrigerator, Heat Exchanger, Porosity, Fuzzy Logic, CFD

\section{Introduction}

In the history of cryogenics the invention of Pulse tube refrigerator was performed by Gifford and Logesworth [1] in the year of 1964 at the Syracuse University. It was known as a Basic Pulse Tube Refrigerator (BPTR). Pulse tube refrigerator is used for helium liquefaction, magnetic resonance and aerospace applications. It has the advantages of other type of cryocoolers due to its high reliability, no moving part at the cold end region, low price and the low magnet interference. Mikulin et al. [2] was the first modifier who brought a modification to the classical (BPTR) type by adding a small orifice valve in 1984, which is responsible for the increase the in its efficiency. The addition of small orifice caused an improvement in the phase between the velocity and temperature and as a result more enthalpy flows near the hot heat exchanger. Such types of Refrigerator are known as an Orifice Type Pulse Tube Refrigerator (OPTR). After that various researchers brought various new type of constructional modifications to enhance the cooling capacity and cool down behaviour. Zhu et al. [3] introduced a Double inlet Orifice Pulse Tube Refrigerator (DIOPTR) in which a by pass was directly connected to the reservoir inlet from the compressor outlet, where the surplus amount of fluid passed to the compressor and decreased the regenerator losses. Minimum temperature of nearly $(3.5 \mathrm{~K})$ was achieved with multi stages pulse tube refrigerator [4-6]. Beside from BPTR, OPTR and DIOPTR configurations discussed above, various alternative configurations have been proposed. For example, Zhu et al. [7] proposed an active-buffer pulse tube refrigerator in which more than one reservoir was attached. The temperature of $(80 \mathrm{~K})$ was achieved with $(11 \%)$ of Carnot efficiency. Pan et al. [8] experimentally studied a 4-valve pulse tube refrigerator and achieved a $(57 \mathrm{~K})$ temperature at $(100 \mathrm{~W})$ with an input power of $(7 \mathrm{~kW})$. The most recent type developed of pulse tube refrigerators is the Inertance-Type Pulse Tube Refrigerator (ITPTR). In this type, a long inertance tube is replaced instead of the small orifice between the cold end and reservoir. The addition of 
inertance tube causes a batter phase relation between mass flow rate and pressure than the orifice type. Chen et al. [9] performed a CFD analysis by using the commercial software FLUENT to study the multi-dimensional flow characteristics and cool down behaviour of pulse tube refrigerator. One major assumption of this CFD analysis using FLUENT package is that the regenerator efficiency was assumed to be (100\%). This was studied by Ashwin et al. [10] by considering a thermally non - equilibrium medium of porous region inside the regenerator. Cha et al. [11] gave a computational fluid dynamics approach to solve the single stage iterance pulse tube refrigerator using well CFD solution software FLUENT and studied the multi-dimensional flow effects. However, various mathematical and numerical fascinating investigations had been done by different researchers to study the multi-dimensional flow effect, non-linear process, thermodynamic process and oscillatory flow [12]. The main objective of the first section is to study the pressure fluctuation as well as the cool down behavior at cold end due to varying in the porosity inside the porous region. It is reported by the use of CFD simulation of the governing equations with the help of FLUENT software package.

\section{Fuzzy Logic Technique}

The advantage of the application of soft computing technique is to predict the heat transfer and the fluid flow variables throughout a complicated domain. CFD has some disabilities where both the accuracy and the stability are the most two important drawbacks. In general, pulse tube refrigerator problems are highly non-linear and simulation takes long timing and high computation cost. Therefore, the soft computing techniques ( such as, Artificial Neural Network, Fuzzy Logic, Adaptive Neuro-Fuzzy Inference, Genetic Algorithm, etc.) can be considered as most powerful tools to predict the fluid flow and heat transfer analysis. Fuzzy logic is the recently most using technique in systems where a robust control is required, mainly in the plant parameter variation. Generally, it is a non-linear adaptive technique based on the artificial intelligence method. The principal concept of the fuzzy set theory is purely self-generated and natural. The great advantage of fuzzy set theory is that, it does not require any details related with the mathematical model of plant. Fuzzy logic is introduced for the first time by Zaden [13] in the year of 1965. The application of fuzzy logic reduces the cost of experiments during the problems modeling in research works. Selimefendigil and Öztop [14] employed the fuzzy logic algorithm to predict the mixed convection of a square cavity attached with thin inclined adiabatic fins. The inputs and outputs parameters required for fuzzy based identification procedure were generated using CFD code. They compared the predicted fuzzy model with the CFD results and found that the error between them within acceptable range. Fuzzy logic had been used also by Karami et al.[15] to predict the heat transfer of an air cooled heat exchanger assembled with various types of tube inserts for a range from Reynolds number $(\operatorname{Re}=3000)$ to $(\operatorname{Re}=17000)$. They predicted an acceptable range of error [i.e. $0.68 \%$ ] between experimental results and predicted fuzzy technique results. The temperature distribution inside the furnace surface had been predicted by Wang et al. [16] using the fuzzy logic technique. They considered the deviation between the measured temperature at furnace wall and computed temperature as an input parameter to the fuzzy model. They also compared the predicted fuzzy results with Genetic Algorithm (GA) and reported that fuzzy logic had higher accuracy than GA. Şahin [17] used the fuzzy logic algorithm and genetic algorithm to optimize the single stage air-source vapor compression heat pump system. The thermodynamic properties were also calculated .They found a good agreement with the actual results. Juntaek et al.[18] were used the soft computing technique (ANFIS) to control the convergence of the finite volume computational fluid dynamics algorithm. While, Mahmoud and Ben-Nakhi [19] were utilized three types of neural network for predicting the thermal and flow variables inside a partitioned enclosure. The results showed an excellent prediction of neural network results with the corresponding CFD results. Xie et al. [20] investigated experimentally three types of shell and tube heat exchangers with segmental baffles or continuous helical baffles. The obtained experimental data were prepared for training and testing the neural network configuration using the back propagation algorithm. They revealed that the error was less than $(2 \%)$ between the predicted and the experimental results.Varol et al.[21] utilized the soft computing methods [ i.e., Adaptive-Network-Based Fuzzy Inference System (ANFIS) and Artificial Neural Network (ANN) to predict the free convection thermal and flow variables inside a triangular enclosure. CFD approach was used to solve the governing equations and the obtained results were used for training and testing the (ANN) and (ANFIS) methods. The comparison between CFD and soft computing methods explained an acceptable range of error. They also revealed that (ANFIS) was more powerful technique than (ANN) method. Aminossadati et al. [22] were used CFD analysis to testing and validating an (ANFIS) approach of the laminar mixed convection in a two-sided lid-driven enclosure filled with nano fluid. They reported that the predicted results from (ANFIS) was well agree with CFD results within acceptable range of error. Liu et al. [23] used the fuzzy logic method to control the convergence in the numerical fluid dynamic simulation using SIMPLE algorithm. Diaz et al. [24] had used (ANN) technique to control the temperature of air passing over a heat exchanger. This method was used to predict the dynamic behavior of a heat exchanger. Dragojlovic and Kaminski [25] used the fuzzy logic to guide the under- relaxation of the discretized Navier-Stroke equations during the simulation of turbulent flow and heat transfer problems. The results illustrated that the application of fuzzy logic improved the computational 
effort of solving various types of CFD problems with different geometries, boundary conditions and material properties. Islamoglu and Kurt [26] and Islamoglu et al. [27] predicted the heat transfer rate using (ANN) approach for a wire on the tube heat exchanger. They also predicted the mass flow rate and out let temperature for air flow in corrugated channels. In the present work, the diameter and the length of pulse tube and regenerator are considered as a variable parameters in the numerical procedure, while the remaining parameters are considered constant.

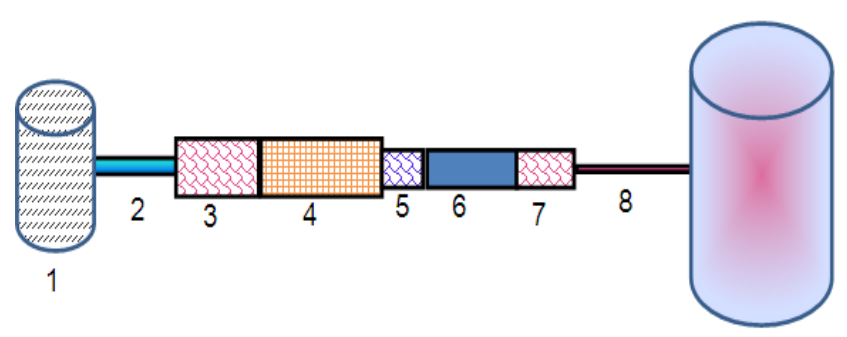

Figure 1. Schematic diagram of computational domain of ITPTR : 1 compressor, 2 - transfer line, 3 - after cooler, 4 - regenerator, 5-cold heat exchanger, 6 - pulse tube, 7 - hot heat exchanger, 8 - inertance tube, 9 reservoir.

\section{Description of Problem Geometry}

Figure 1 shows the line diagram of Inertance-Type Pulse Tube Refrigerator (ITPTR) model along with its individual associated components. The whole system consists of a compressor which produces the fluctuating pressure for the system and it is connected to a heat exchanger through a transfer line known as after cooler which extracting the heat to the surrounding generated by the compressor. The heart of the whole system is a regenerator, whose effectiveness is responsible for the cooling capacity of the pulse tube refrigerator. The cold heat exchanger is the cold region where the cooling load is supplied to the system. The heat is extracted from the system with the help of a hot heat exchanger. In between the hot and cold heat exchangers there is a pulse tube which is responsible for producing the phase difference between the mass flow rate and the fluctuating pressure. The reservoirs store the working fluid and acting as a buffer. It is separated from the cold heat exchanger either by an inertance tube for (ITPTR) or by an orifice for (OPTR).

\subsection{Details of Modelling}

All modeling details and meshing of the linear coaxial 2D axi-symmetric inertance pulse tube refrigerator model is done by using the modeling software GAMBIT. The experimental non-linear model is turned into an equivalent present linear model. The dimensions of the whole system are shown in Table 1 . The numbers of grid points are varied from (3643) to (5217) for the purpose of a grid independency test .To operate the compressor piston head a suitable (DEFINE_CG_MOTION) user define function (UDF) which was chosen from FLUNT user manual [28] was considered. This UDF is written in the $\mathrm{C}$ language, compiled and attached to the head of the piston. The two head piston oscillate about its center with a relation of $\left[a=a 0^{*}\right.$ $\sin *(\omega \mathrm{t})]$. Where ' $\mathrm{a}$ ' is the piston displacement and $(\mathrm{a} 0=$ $0.0045 \mathrm{~m})$ is the amplitude with a time increment is assumed of $(0.0007 \mathrm{~s})$ while the piston head velocity is related with the correlation $\left[\mathrm{v}=\mathrm{a} 0 * \omega * \cos ^{*}(\omega \mathrm{t})\right]$. Where ' $\mathrm{v}$ ' is the piston head velocity. For regenerator porous media region the parameters were taken from Ashwin et al. [10] which are inertial resistance $\left(76090 \mathrm{~m}^{-1}\right)$ and permeability $\left(1.06 \times 10^{-10} \mathrm{~m}^{2}\right)$. Steel is chosen as a matrix material for regenerator. The working fluid in the present work is Helium, while the various properties ( i.e., thermal conductivity, viscosity and specific heat) of the fluid are taken as temperature dependent from NIST data base. No wall thickness is considered as an assumption for the present analysis.

Table 1. Dimensions of the (ITPTR) considered for the present analysis

\begin{tabular}{|c|c|c|c|}
\hline constituent part & Diameter $(\mathrm{m})$ & Length $(\mathrm{m})$ & Boundary condition \\
\hline (1) Compressor & 0.019 & 0.0075 & Adiabatic \\
\hline (2) Transfer line & 0.003 & 0.101 & Adiabatic \\
\hline (3) After cooler & 0.008 & 0.02 & $300 \mathrm{~K}$ \\
\hline (4) Regenerator & 0.008 & 0.058 & Adiabatic \\
\hline (5) Cold heat exchanger & 0.006 & 0.0057 & Adiabatic \\
\hline (6) Pulse tube & 0.005 & 0.125 & Adiabatic \\
\hline $\begin{array}{c}\text { (7) Hot heat exchanger } \\
\text { (8) Inertance tube } \\
\text { (9) Reservoir }\end{array}$ & $\begin{array}{c}0.008 \\
0.00085\end{array}$ & $\begin{array}{c}0.01 \\
0.088\end{array}$ & $\begin{array}{c}\text { 300 K } \\
\text { Adiabatic } \\
\text { Adiabatic }\end{array}$ \\
\hline
\end{tabular}




\section{Mathematical Modelling}

The governing equations for the present $2 \mathrm{D}$ axisymmetric transient model are the continuity equation, momentum equation in both the axial as well as in radial directions together with the energy equation for the solid matrix inside the porous region which was written with no swirl assumption. Two extra source terms, both in axial as well as in radial directions are considered for the porous region to calculate momentum losses. For the rest of porous medium these values are assumed to be zero and the solid matrix inside the porous region is considered as a homogeneous material.

Continuity Equation

$$
\frac{\partial}{\partial t}[\xi \rho]+\frac{1}{y} \frac{\partial}{\partial y}\left[\xi r \rho_{y}\right]+\frac{\partial}{\partial x}\left[\xi \rho_{f} v_{x}\right]=0
$$

Momentum Equation

For axial direction

$$
\begin{aligned}
& \frac{\partial}{\partial t}\left[\xi \rho v_{x}\right]+\frac{1}{y} \frac{\partial}{\partial x}\left[\xi r v_{x} v_{x}\right]+\frac{1}{y} \frac{\partial}{\partial y}\left[\xi y \rho_{f} v_{x} v_{y}\right]=-\frac{\partial \xi p}{\partial y}+ \\
& \frac{1}{y} \frac{\partial}{\partial y}\left\{y \mu\left(2 \frac{\partial \xi v_{x}}{\partial x}-\frac{2}{3}(\vec{\nabla} \xi \cdot \vec{v})\right)\right\}+\frac{1}{y} \frac{\partial}{\partial y}\left\{y \mu\left[\frac{\partial \xi v_{x}}{\partial y}+\frac{\partial \xi v_{y}}{\partial y}\right]\right\}+S_{x}
\end{aligned}
$$

For radial direction

$$
\begin{aligned}
& \frac{\partial}{\partial t}\left[\xi \rho_{f} v_{y}\right]+\frac{1}{y} \frac{\partial}{\partial x}\left[\xi r v_{x} v_{y}\right]+\frac{1}{y} \frac{\partial}{\partial y}\left[y \xi \rho_{f} v_{y} v_{y}\right]=-\frac{\partial p}{\partial y}+ \\
& \frac{1}{r} \frac{\partial}{\partial x}\left\{2 x \mu\left(\frac{\partial v_{x}}{\partial x}-\frac{1}{3}(\vec{\nabla} \cdot \vec{v})\right)\right\}+\frac{1}{y} \frac{\partial}{\partial y}\left\{2 y \mu\left[\frac{\partial v_{x}}{\partial y}-\frac{1}{3}(\vec{\nabla} \cdot \vec{v})\right]\right\} \\
& +\frac{2 \mu}{y}\left[\frac{(\vec{\nabla} \cdot \vec{v})}{3}-\frac{v_{y}}{y}(\vec{\nabla} \cdot \vec{v})\right]+S_{y}
\end{aligned}
$$

Where Sx and Sy are the two source terms in both the axial and radial directions which values are zero for nonporous zone. But, for the porous zone the source term which is solved by the solver is given by the following equations :-

$$
\begin{aligned}
& S_{x}=-\left(\frac{\mu}{\psi} v_{x}+\frac{1}{2} C \rho_{f}|v| v_{x}\right) \\
& S_{y}=-\left(\frac{\mu}{\psi} v_{y}+\frac{1}{2} C \rho_{f}|v| v_{y}\right)
\end{aligned}
$$

In the above equations the first term is called the Darcy term and the second one is called the Forchheimer term which are responsible for the pressure drop inside the porous zone. Energy Equation:

$$
\frac{\partial}{\partial t}\left(\xi \rho E_{f}+(1-\xi) \rho_{s} E_{s}\right)+\vec{\nabla} \cdot\left(\vec{v}\left(\rho_{f} E_{f}+p\right)\right)=\vec{\nabla} \cdot\left(k \vec{\nabla} T_{f}+\tau \cdot \vec{v}\right)
$$

Where the energy equation for the solid matrix is given by :-

$$
\frac{\partial}{\partial t}\left(\rho_{f} E_{f}\right)=\vec{\nabla} \cdot\left(k_{s} \vec{\nabla} T_{s}\right)+S_{s}
$$

Energy equation for gas

$$
\frac{\partial}{\partial t}\left(\rho_{f} E_{f}\right)+\vec{\nabla} \cdot\left(\vec{v}\left(\rho_{f} E_{f}+p\right)\right)=\vec{\nabla} \cdot\left(k \vec{\nabla} T_{f}+(\tau \cdot \vec{v})\right)+S_{G}
$$

For non-porous zones, the energy source term (SG) is zero. However, in the porous zones, it is given by :-

$$
S_{G}=\alpha A_{v}\left(T_{s}-T_{f}\right) / \phi .
$$

Where $\rho *=\rho_{f}\left(T_{H}\right) / \rho_{f}\left(T_{a v}\right)$. The quantities $\left(\mathrm{T}_{\mathrm{av}}\right)$ and $\left(\mathrm{T}_{\mathrm{H}}\right)$ are, the average temperature of the gas inside the regenerator and the hot end regenerator temperature respectively.

\subsection{Initial and Boundary Conditions}

The governing equations for 2D model as described above are solved by using Fluent. The mean charge pressure is $(30$ bar) at which the total system operates. The sinusoidal pressure variation inside the whole system is due to the compressor head motion which is operated with a UDF as stated above. For an ideal condition of operation, the simulation started with $300 \mathrm{~K}$ operating temperature. The working fluid is Helium, assumed for simulation with temperature dependent viscosity. The wall temperature of both the cold and hot heat exchangers are maintained at 300 $\mathrm{K}$ while the rest component walls are operated with an adiabatic condition. For better solution, the convergence of (40 inner steps) with a time step for iteration of $(0.0004 \mathrm{~s})$ is needed. It will take more than 15 days to reach a periodic state with the CPU configuration of (8 GB) of RAM and (3.1) $\mathrm{GHz}$ processor.

\subsection{Fuzzy Inference System}

The process of generating mapping from a given input crisp to output crisp using the fuzzy logic is named as fuzzy inference process. It proceeds with the fuzzification of crisp input by considering fuzzy logic operator, membership function and fuzzy rules (IF-THEN rules). The block diagram of a typical fuzzy ruled based system consists of : (a) fuzzification (b) knowledge base (c) inference system and (d) Defuzzifier. From the mathematical point of view, a fuzzy logic is based on the fuzzy set theory. In fact, a fuzzy set is a set without a crisp, clearly defined boundary. In fuzzy set, numbers of membership are permitted and defined between (0) and (1). A number of different types of membership functions (MF) such as triangular, trapezoidal, piecewise linear, Gaussian, two-sided or singleton have been proposed for fuzzy control system. In fact, triangular MFs are commonly used due to its simplicity to implement in the fuzzy control system. The fuzzy set is different from a crisp by introducing of member function. If ' $\mathrm{X}$ ' is a finite set considering as universe set then :-

$$
X=\left\{x_{1}, x_{2}, x_{3}, \ldots \ldots x_{1},\right\}
$$

Where (X1) is a single element. The subset $\mathrm{A}$ of $\mathrm{X}$ 
consisting of the single element (X1) can be defined as :

$$
A=\{x, \mu A(x) / x \in X\}
$$

Where $\mu \mathrm{A}(\mathrm{x})$ is called MF of $\mathrm{x}$ in $\mathrm{A}$. The degree of MF is expressed by a real number in the interval $[0,1]$. The triangular MF is described by three parameters a , b and c and defined by the following expression :-

$$
f(x, a, b, c)=\max \left[\min \left[\frac{x-a}{b-a}, \frac{c-x}{c-b}\right], 0\right]
$$

Where the parameters (a) and (b) defined the "feet" of the triangle while, (c) defined the peak .For more elaborately the above equation can be written as :-

$$
\mu_{A}(x)=\left\{\begin{array}{lc}
0 & \mathrm{x} \leq \mathrm{a} \\
\frac{x-a}{b-a} & \mathrm{a} \leq \mathrm{x} \leq \mathrm{b} \\
\frac{c-x}{c-b} & \mathrm{~b} \leq \mathrm{x} \leq c \\
o & \mathrm{c} \leq \mathrm{x}
\end{array}\right\}
$$

It is useful to mention that, fuzzy rule base is responsible to make inference in a fuzzy system. While, IF-THEN constructions, that have the general form "IF A THEN B" where $\mathrm{A}$ and $\mathrm{B}$ are propositions containing a linguistic variables. A is called premise and $B$ is the consequence of the rule. From the other hand, there are two types of fuzzy inference such as Mamdani type inference and Sugeno type inference which are widely employed in different fields of applications. The two-dimensional Mamdani type fuzzy inference is most commonly used in a close loop control system. This is due to its advantage by making the steady state error tends to be zero. In the Mamdani inference the fuzzy rules are defined as :-

For rule $\mathrm{Ri}$ if $\mathrm{x} 1$ is Ali and $\mathrm{x} 2$ is $\mathrm{A} 2 \mathrm{i}, \ldots \ldots \mathrm{xs}$ is Asi then yi is $\mathrm{Ci}$,

Where $i=1,2, \ldots . . M$

$\mathrm{M}=$ Total number of fuzzy rule

$\mathrm{xi}=$ input variables

$\mathrm{yi}=$ output variables

The aggregate output for $\mathrm{M}$ rule is

$$
\begin{gathered}
\mu_{c_{i}}\left(y_{i}\right)=\max \left[\min \left(\mu_{A_{i i}}\left(x_{1}\right), \mu_{A_{2 i}}\left(x_{2}\right), \ldots \ldots . . . \mu_{A_{s i}}\left(x_{s}\right)\right)\right] \\
i=1,2,3, \ldots \ldots . M
\end{gathered}
$$

\subsection{Defuzzification}

Defuzzification is the final step of a fuzzy inference system. It is a process to select a representative element from the fuzzy output (C) inferred from the fuzzy control algorithm. The most often used defuzzification operators are center of area gravity, center of sums, first of maxima, last of maxima and height defuzzification. For more details relating to the defuzzification, the reader can be go back to Dragojlovic and Kaminski [25]. Table 2 illustrates the selected structure of the proposed fuzzy model.
Table 2. Selected structure of the proposed fuzzy model

\begin{tabular}{|c|c|}
\hline Types of fuzzy inference system & Mamdani \\
\hline Inputs/output & $4 / 1$ \\
\hline Input MF types & Triangular \\
\hline Output MF types & Triangular \\
\hline Number of input MF & 5 \\
\hline Number of output MF & 9 \\
\hline Rules weight & 1 \\
\hline Number of fuzzy rules & 220 \\
\hline And method & Min \\
\hline Implication method & Max \\
\hline Aggregation method & Centroid area \\
\hline
\end{tabular}

\section{Numerical Solution Procedure}

The most important factor in the numerical simulation is that the suitable numerical scheme. The axisymmetric, unsteady, cell based second-order implicit time; physical velocity with segregated solver are considered for the present analysis. PISO algorithm with a PRESTO (Pressure Staggered Option) scheme for the pressure-velocity coupling is used for the pressure correction equation. Suitable underrelaxation factors [12] for momentum, pressure and for energy had been used to get the better convergence. Quadlateral as well as triangular cells were used for the computational domain. For all governing equations, the convergence of the discretized equations are said to have been achieved when the whole field residual was kept at $\left(10^{-6}\right)$.

\subsection{Grid Independency and Model Validation}

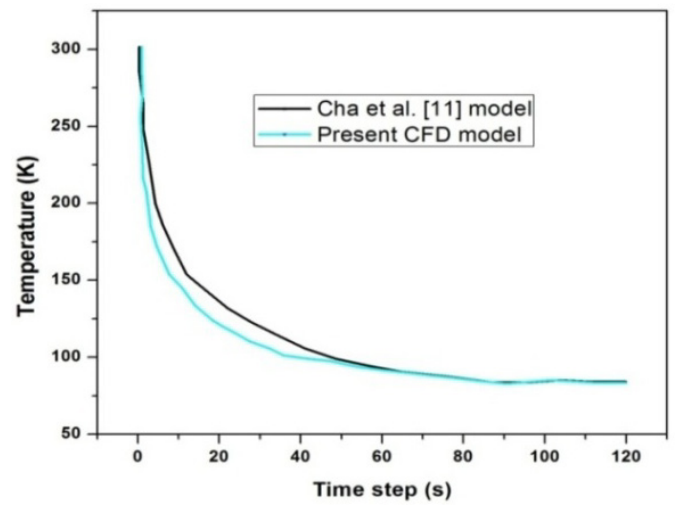

Figure 2. Cool down temperature for model validation

A model validation test is carried out against the previous work by Cha et al. [11] to check the accuracy of the model and the solution method of the present work. It is noticeable from Fig. 2 that the steady state temperature is reached after (120s) for both cases after which there is no change in temperature with respect to time. The Cha et al. [11] model reporting a temperature of ( $87 \mathrm{~K})$ using $(4200)$ number of cells, while in the present work it is found a ( $86 \mathrm{~K})$ using (3900) cells. This comparison verifies the accuracy of the present numerical model. Moreover, Table 3 illustrates a 
good comparison between numerical cold end temperature and predicted fuzzy logic results.

Table 3. Comparison between numerical cold end temperature and predicted fuzzy logic results

\begin{tabular}{|c|c|c|c|}
\hline No & $\begin{array}{c}\text { Numerical } \\
\text { result }\end{array}$ & Predicted Fuzzy logic value & Error\% \\
\hline 1 & 116.1 & 115.2 & 0.77 \\
\hline 2 & 87.1 & 86 & 1.26 \\
\hline 3 & 79.3 & 78.6 & 0.88 \\
\hline 4 & 59.8 & 58 & 1.5 \\
\hline 5 & 64.2 & 62.9 & 2.02 \\
\hline 6 & 67 & 66.1 & 1.34 \\
\hline 7 & 119 & 117.3 & 1.42 \\
\hline 8 & 139 & 137.2 & 1.29 \\
\hline 9 & 111 & 109.8 & 1.08 \\
\hline 10 & 75.2 & 74.5 & 0.93 \\
\hline 11 & 52 & 51.4 & 1.15 \\
\hline 12 & 66 & 65.3 & 1.06 \\
\hline 13 & 101 & 100.2 & 0.79 \\
\hline 14 & 119 & 117.8 & 1.00 \\
\hline 15 & 62 & 61.1 & 1.45 \\
\hline 16 & 74 & 73.2 & 1.08 \\
\hline 17 & 92.3 & 90.4 & 2.05 \\
\hline 18 & 104 & 102.6 & 1.35 \\
\hline 19 & 73.5 & 71.8 & 2.31 \\
\hline 20 & 79.1 & 78.3 & 1.01 \\
\hline
\end{tabular}

\section{Results and Discussion}

\subsection{Cool Down Behavior}

The computational simulation will be continuous until a steady periodic saturated state is achieved. In this condition, the Facate Average (FA) temperature of the cold end achieves a steady state. After this steady state condition, there is no change in the cold end temperature. In the present model, it reaches a temperature of ( $46 \mathrm{~K})$ with the supplied dimension, as shown in Fig.3. The whole system wall temperature is plotted here. It is observed that, the compressor temperature is above the operating temperature due to the compression and expansion of fluid inside it. This extra temperature generated inside the compressor is extracted to the surrounding through the after-cooler. Inside the regenerator and due to the presence of extra source term a momentum loss will be occurred. In the source term the presence of two terms such as Darcy and Forchheimer terms in which the pressure drop is directly proportional to the velocity inside the porous zone. The temperature drop contours inside the regenerator are shown in Fig.4.It is observed from the contours that the temperature at the cold end is $(46.5 \mathrm{~K})$.

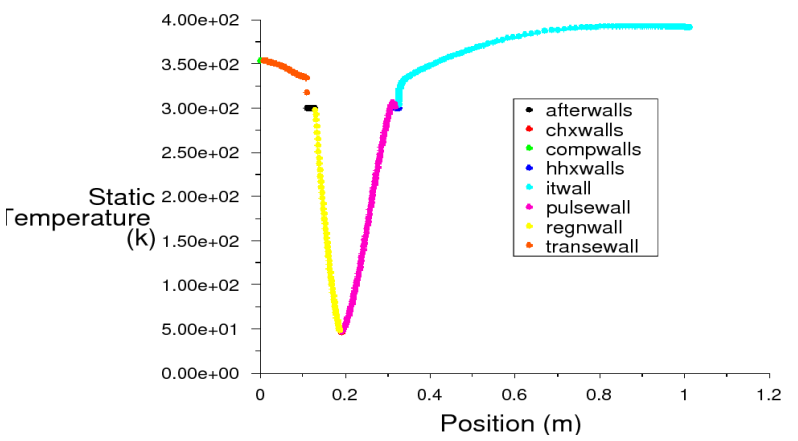

Figure 3. Axial temperature plot varying from compressor to inertance tube after steady state temperature of $46 \mathrm{~K}$ at cold heat exchanger.

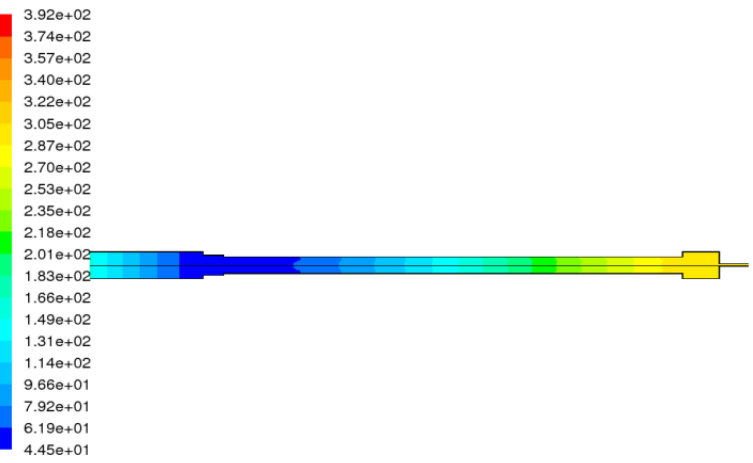

Figure 4. Temperature contours showing the temperature variation inside the pulse tube.

\subsection{The Pressure Variation During the Simulation}

Figures (5-9) show the pressure variation during the simulation inside the whole system. The area weighted average pressure variation inside the cold heat exchanger is shown in Fig. 5 which is sinusoidal in its nature. The pressure variation inside the cold heat exchanger varied from (35.5 bar) up to ( 28.5 bar) which can be clearly observed from this figure. Fig. 6 shows the axial pressure variation inside the total system from the compressor to the reservoir when the piston is placed near to the BDC of the cylinder. At that position the compressor pressure is (36 bar) and the pulse tube pressure is ( $35 \mathrm{bar}$ ), while the reservoir pressure is (32 bar). Fig. 7 shows the axial pressure inside the total system from the compressor to the reservoir when the piston is placed at the middle position during the expansion. At that position, the compressor pressure is (26.5 bar) and the pulse tube pressure is (31.5 bar), while the reservoir pressure is (32.5 bar). When the piston reaches to its top position during the expansion process, the system axial pressure variation is shown in Fig.8. It shows that the maximum pressure inside the reservoir, the minimum pressure inside the compressor and the pulse tube pressure is $(28.5$ bar $)$. During the compression process from (TDC) to (BDC) a pressure variation plot is shown in Fig.9. From the pressure fluctuation analysis during one complete cycle it can be concluded that, when there is a maximum pressure at one end at the same time, the other end of the system has the minimum pressure. This was the main purpose of the present study that to analyze the pressure variation throughout the whole system during a complete cycle. 


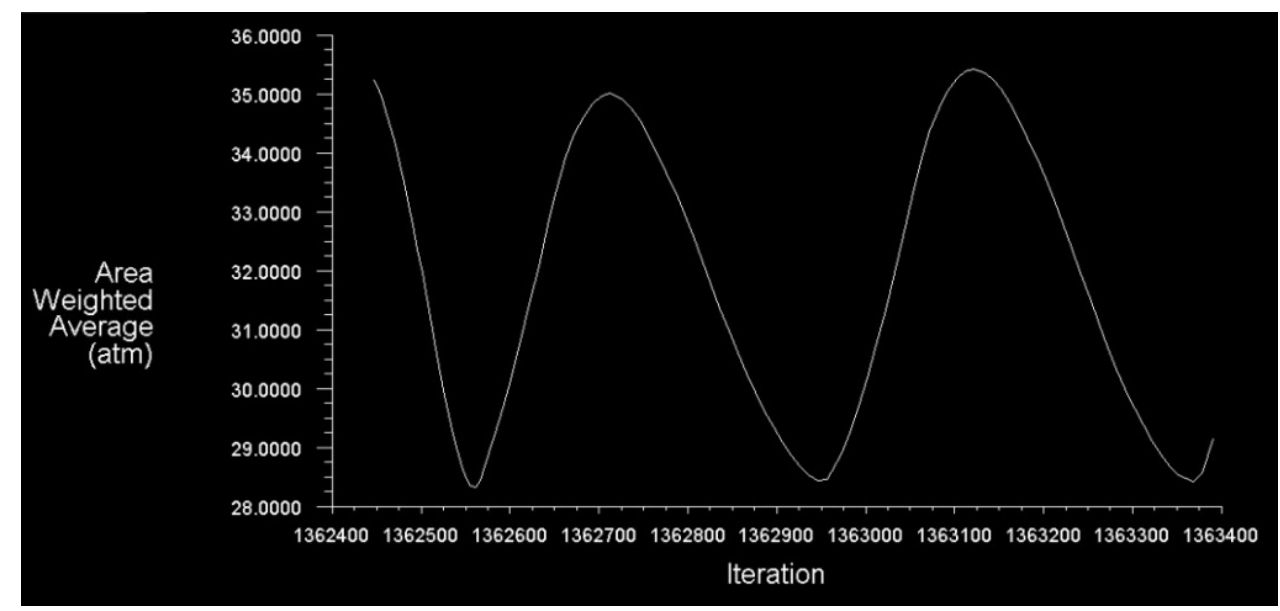

Figure 5. Area weighted average pressure variation inside the cold heat exchanger against iteration curves
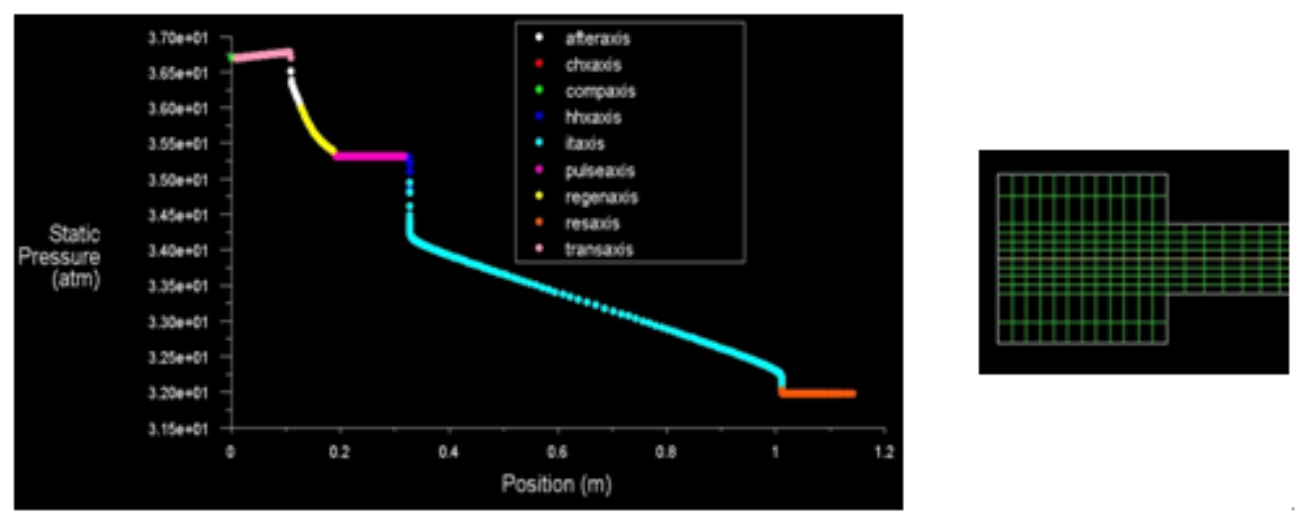

Figure 6. Axial pressure inside the ITPTR, when the piston is near the BDC
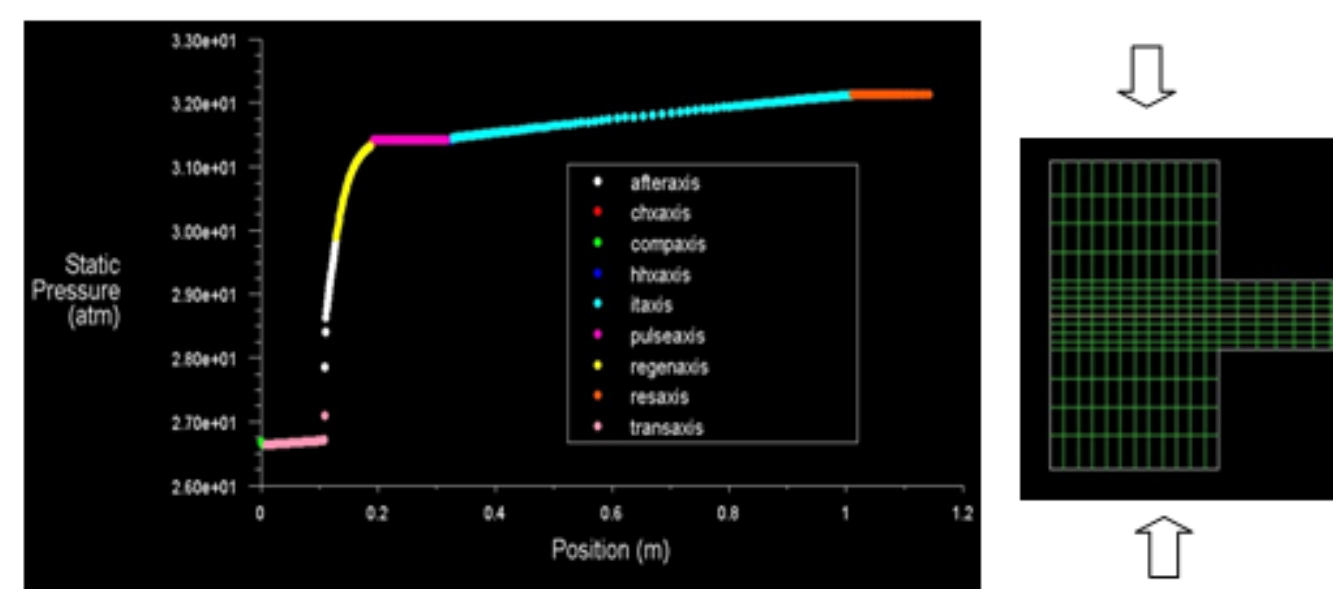

Figure 7. Axial pressure inside the ITPTR, when the piston is in the middle position during the compression 

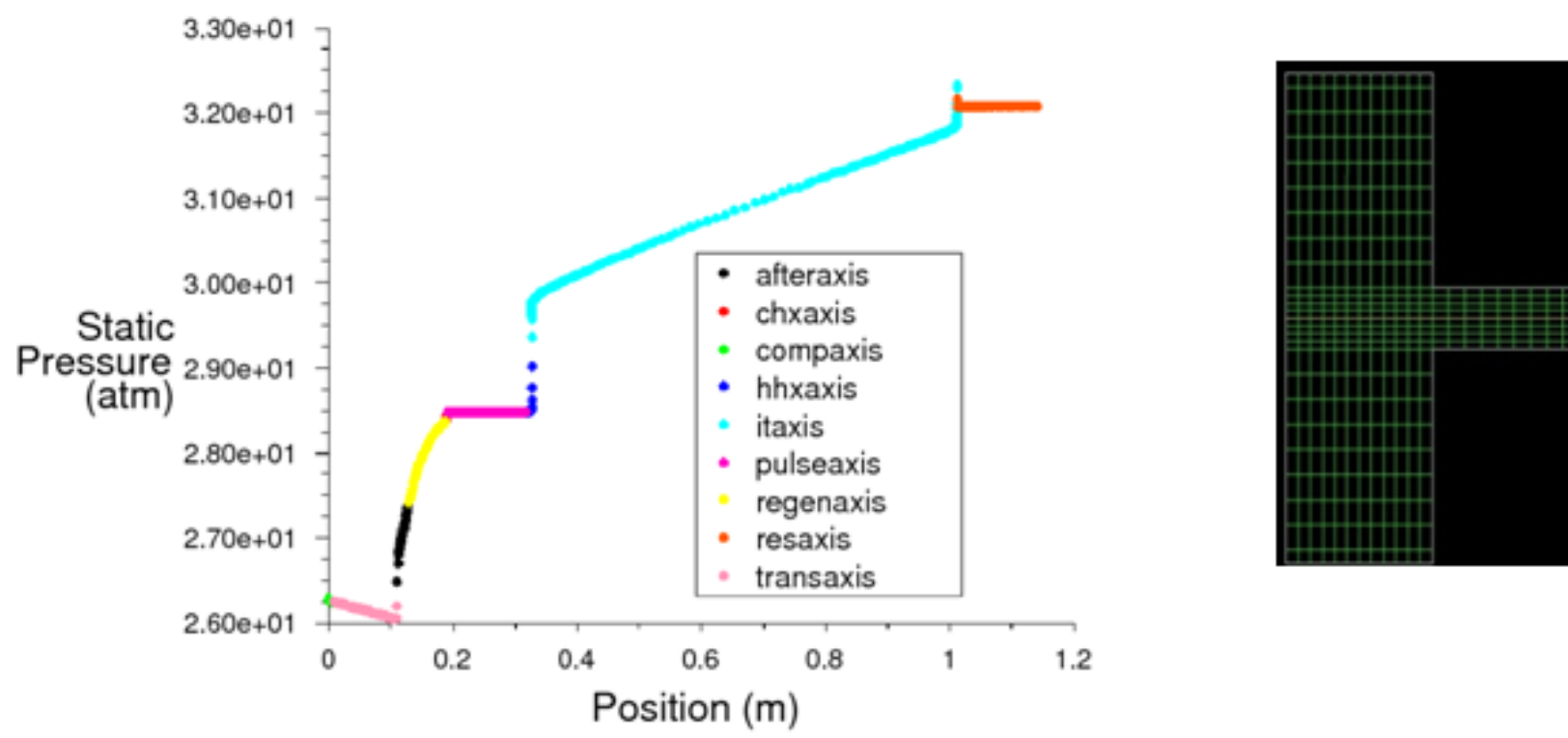

Figure 8. Axial pressure inside the ITPTR, when the piston is near the TDC
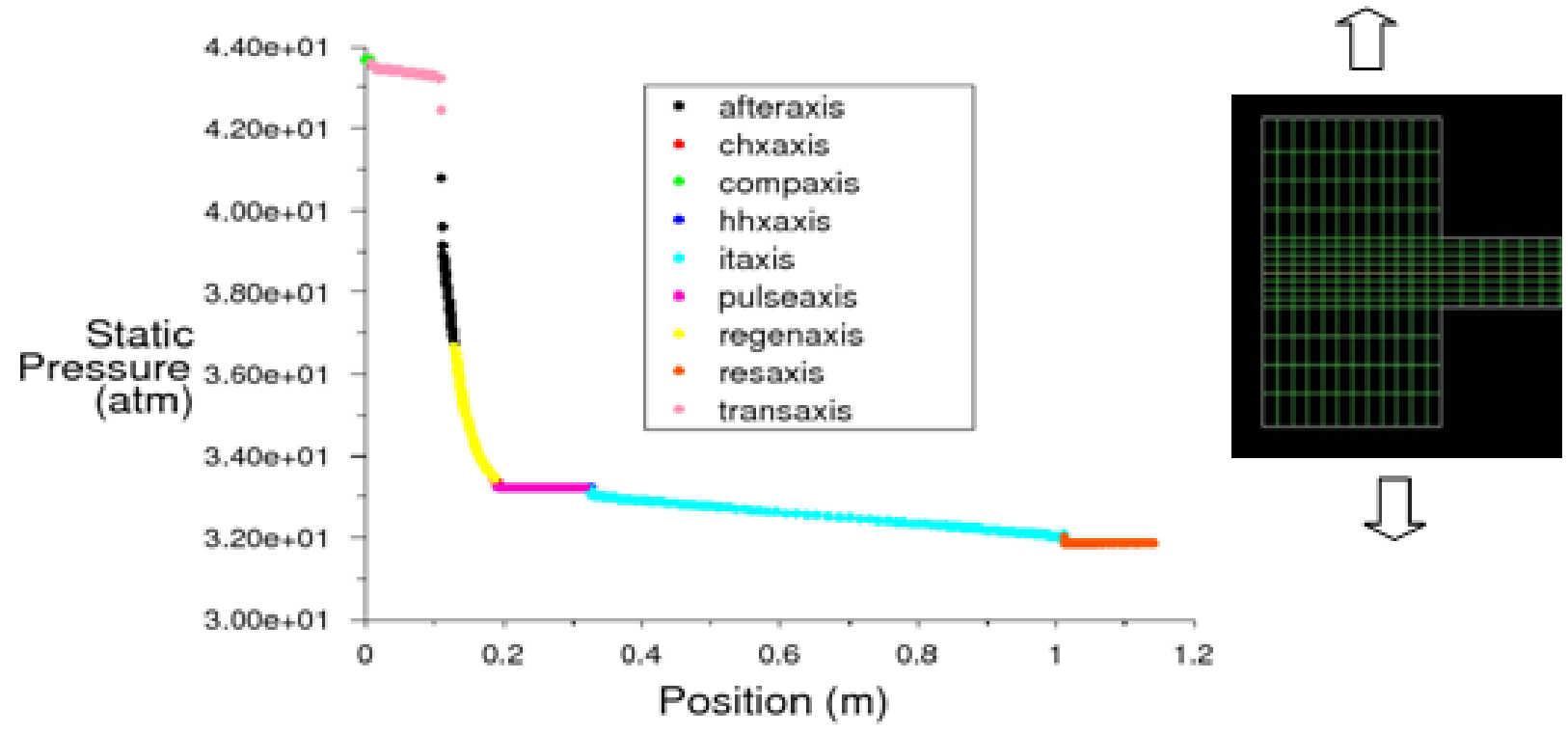

Figure 9. Axial pressure inside the ITPTR, when the piston is in the middle position during the expansion

\subsection{The Porosity Variation During the Simulation}

The most important part of the pulse tube refrigerator is a regenerator. The pulse tube refrigerator performance depends on the effectiveness of the regenerator. In the present work, a number of case studies have been carried out to investigate for which value of porosity it will give a better cooling temperature at the cold end. From the results of the simulation, it was found that at the porosity value of $(0.6)$, the optimum result were found relative to another values as shown in Fig.10.Figures [ 11 (a) and (b)] illustrate respectively the axial temperature distributions of the solid matrix and the fluid inside the regenerator. While the pressure drop inside the regenerator is shown in Fig.12.

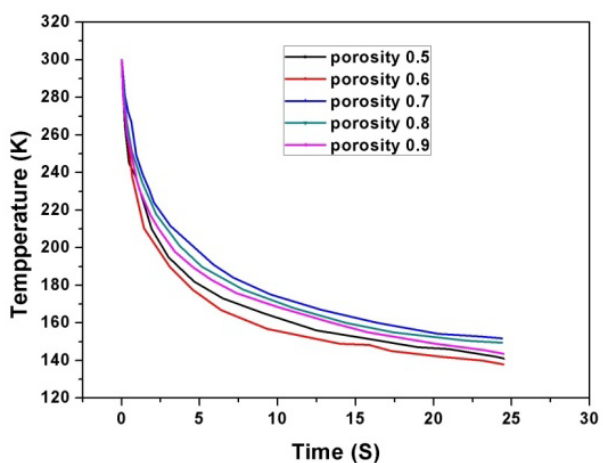

Figure 10. Cool down temperature against the time for different porosities inside the regenerator 

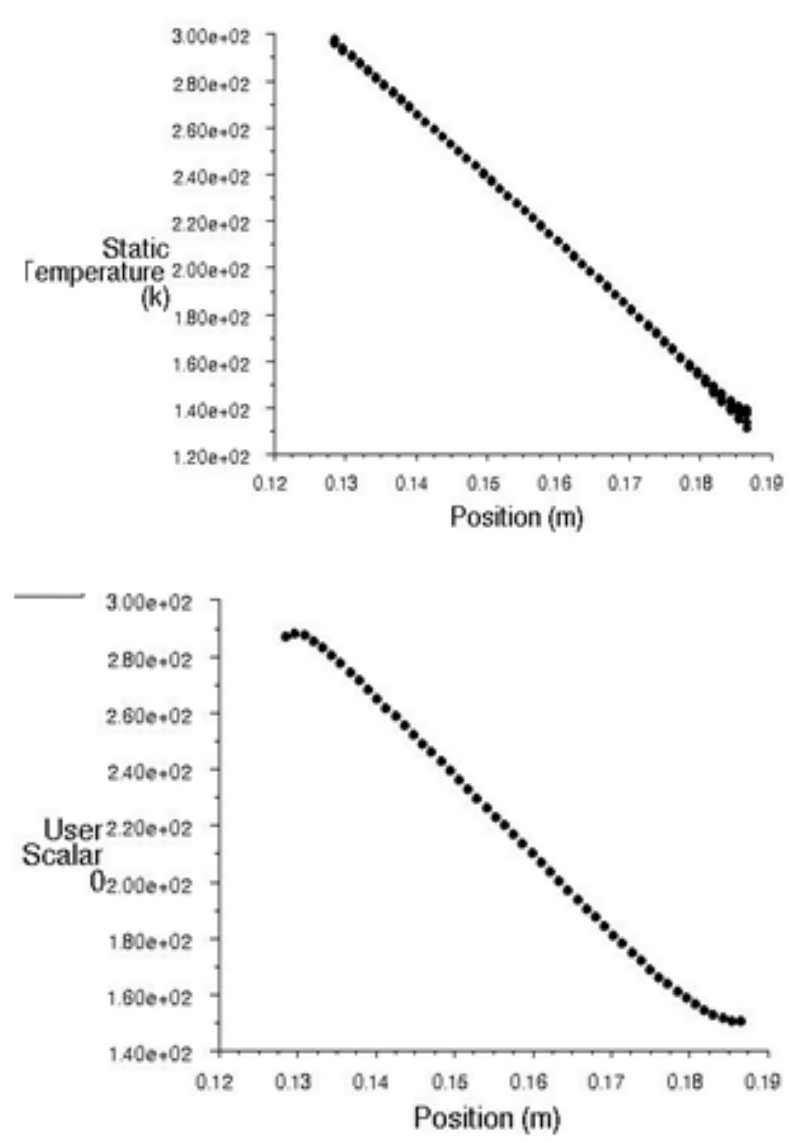

Figure 11. Axial temperature distribution inside the regenerator [ (a) for solid matrix ] , [(b) for fluid ]

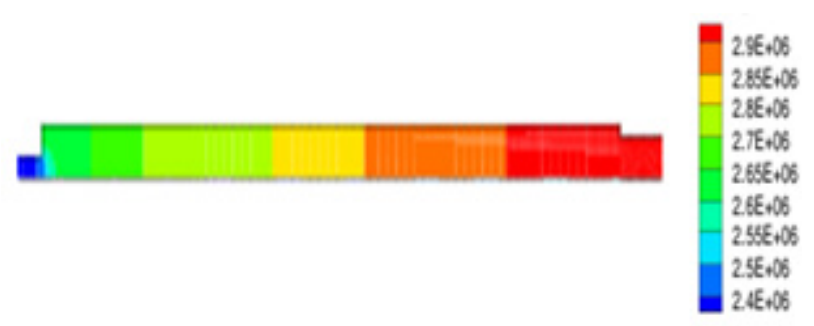

Figure 12. Pressure variation inside the regenerator

\subsection{Thermally Non-Equilibrium Model}

The proposed model can be used for selecting ideal process states to improve the performance of PTR by considering two separate energy equations for the solid matrix and the fluid inside the porous zone. This means that the performance is not $(100 \%)$ which is the main purpose of the present analysis. The solid-fluid interactions are analyzed with the realistic thermal non-equilibrium model for all the porous zones. It is found a higher temperature at the cold heat end for thermal non-equilibrium model than that of thermally equilibrium one as shown in Fig.13. This is due to the presence of Forchheimer term inside the porous medium. From the above investigation, it shows that the inlet fluid and the solid matrix temperatures are the same at exit of the regenerator. Where, the fluid temperature is about (136 K) while the solid matrix temperature is more than $(144 \mathrm{~K})$ as shown in Fig.11.

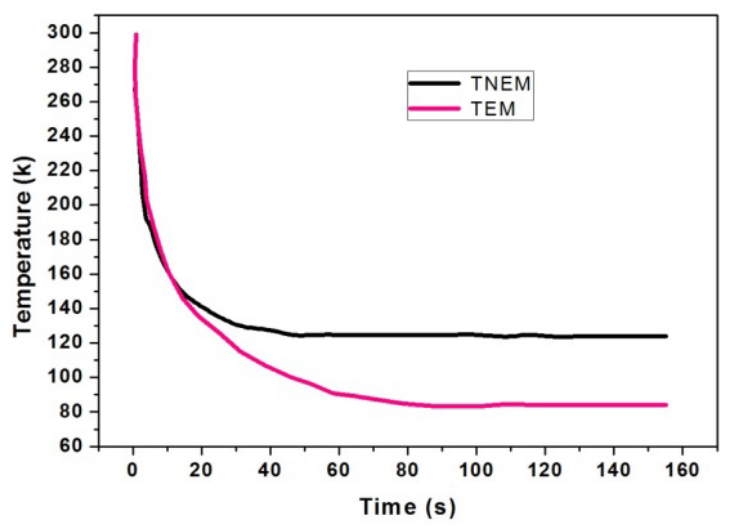

Figure 13. Comparison between cool down characteristics for thermally equilibrium model (TEM) with the corresponding thermally non-equilibrium model (TNEM)

\subsection{Proposed Methodology for Fuzzy Logic}

However, the design analysis of the pulse tube refrigerator is quite difficult due to its complex geometry which affects the performance and cooling behaviour. The fuzzy logic is an appropriate mathematical tool which can compute these linguistic terms accurately and efficiently . The aim of the present investigation is to determine the effect of four main factors, such as diameter of the pulse tube, length of the pulse tube, diameter of the regenerator and the length of regenerator on the heat transfer process from the arrays using fuzzy logic technique. All another parameters such as operating frequency (i.e. $34 \mathrm{~Hz}$ ), porosity, dimension of another components together with no load condition at the cold end are taken the same for all the simulation. The appropriate design of the fuzzy model used in the present study is shown in Fig.14. While, Fig.15 explains that the triangular MF is described by three parameters $a, b$ and $c$. Fig. 16 shows input-output values for PTR in the fuzzy logic. While Figures 17 and 18 illustrate membership functions for input variable pulse tube diameter and length respectively. Figures 19 and 20 explain membership functions for input variable regenerator diameter and length respectively. Finally, rules of the fuzzy logic are shown in Fig. 21.

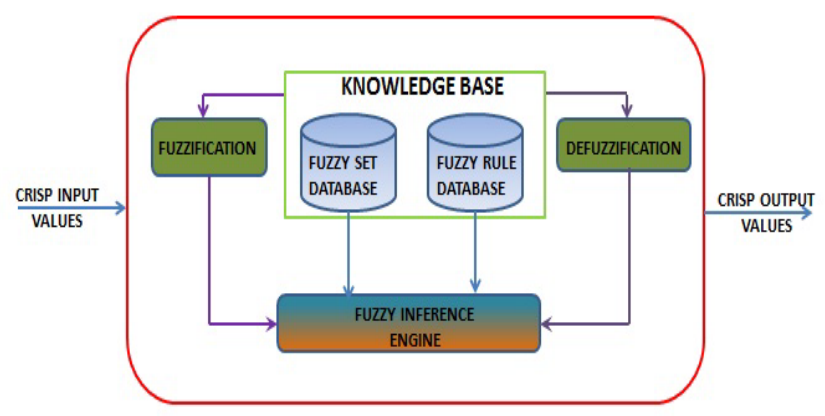

Figure 14. Basic flow chart of fuzzy logic technique used in the present work 


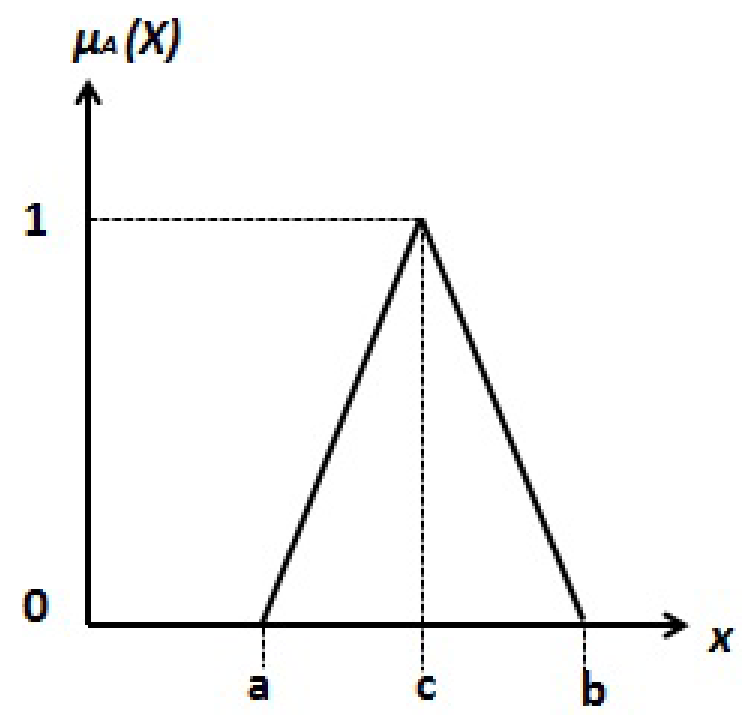

Figure 15. Schematic representation of the triangular membership function

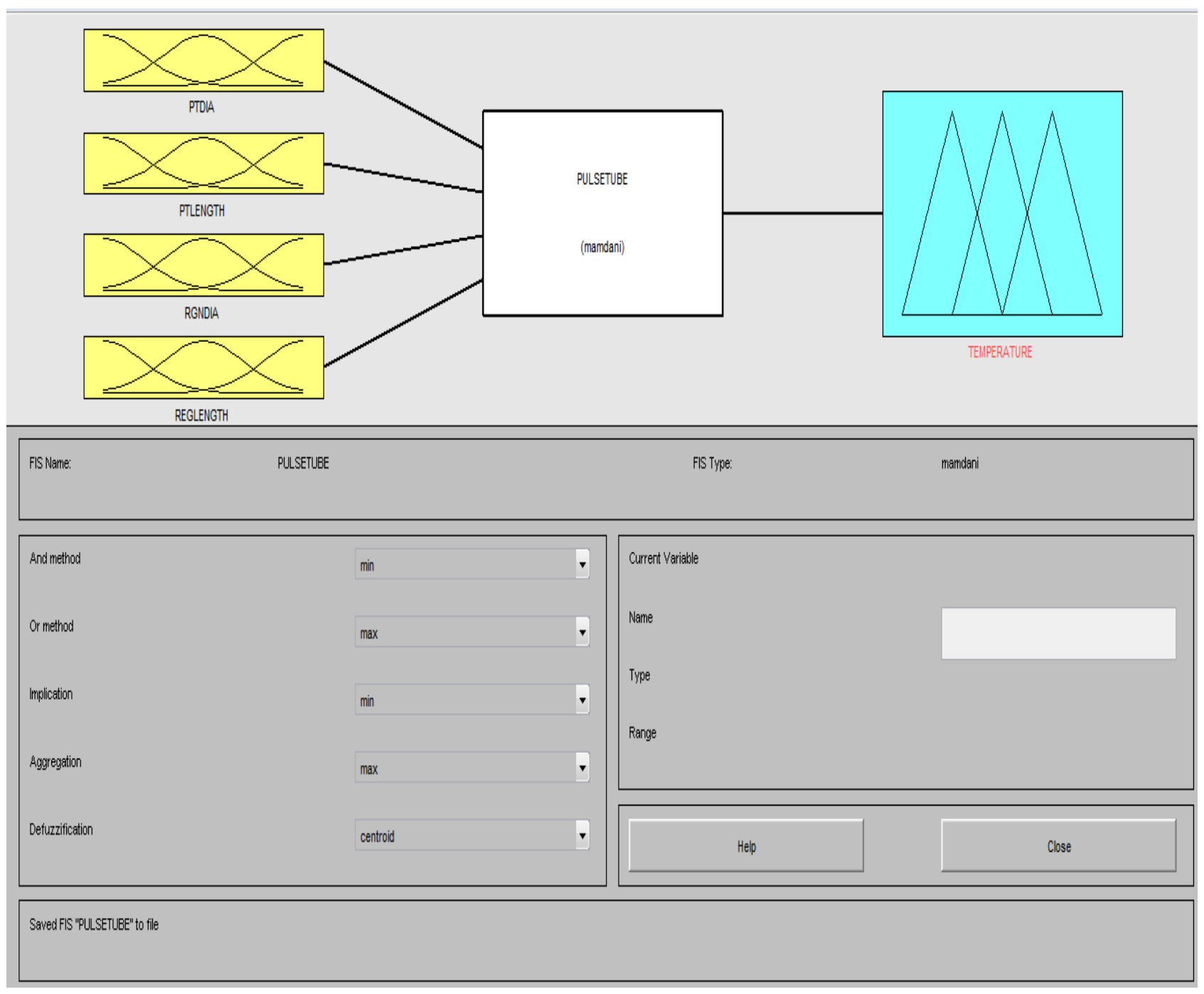

Figure 16. Input-output values for PTR in the fuzzy logic 


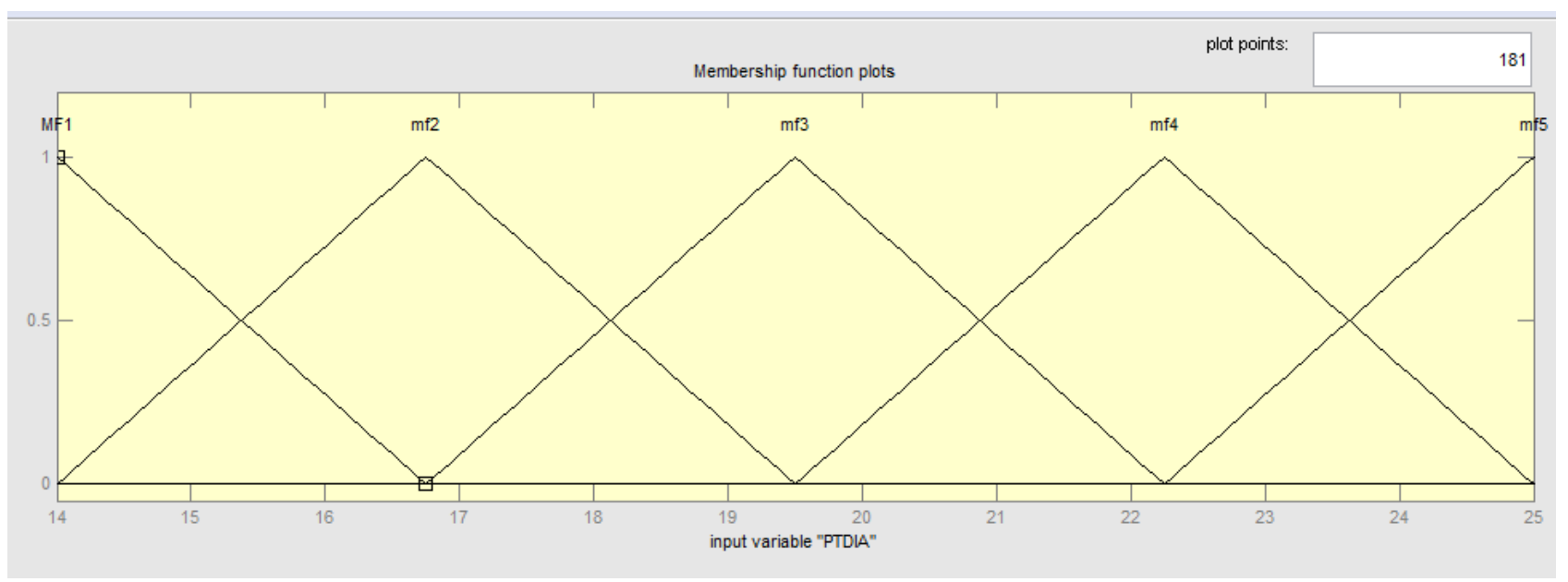

Figure 17. Membership functions for input variable pulse tube diameter.

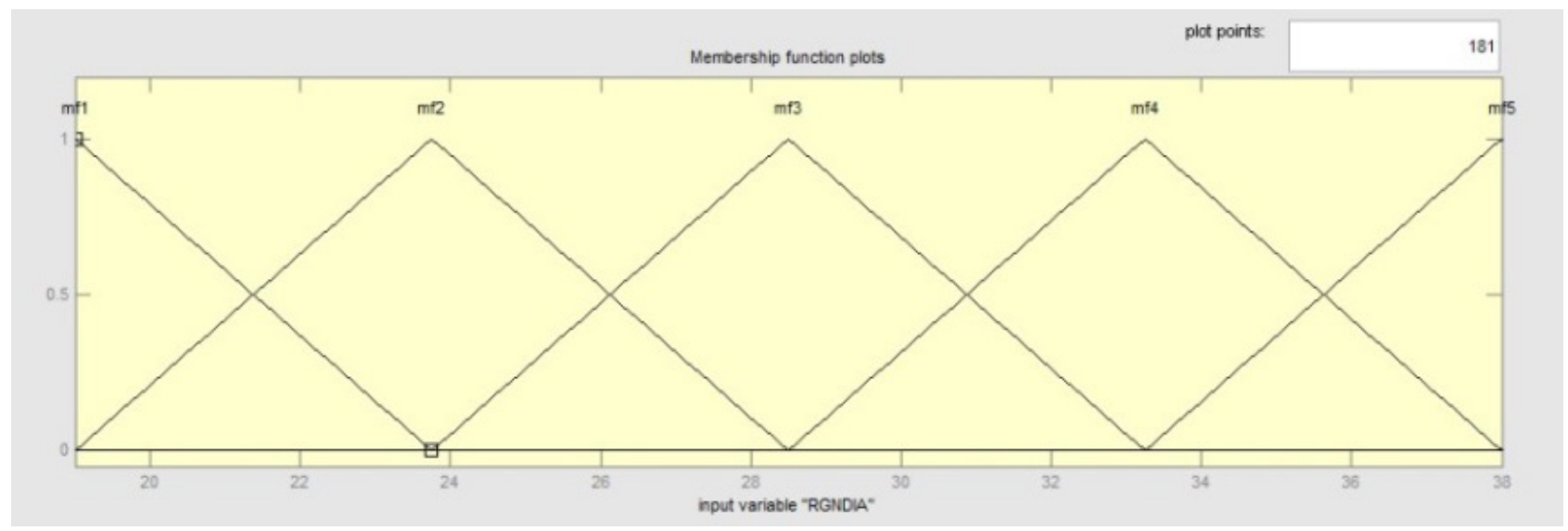

Figure 18. Membership functions for input variable pulse tube length.

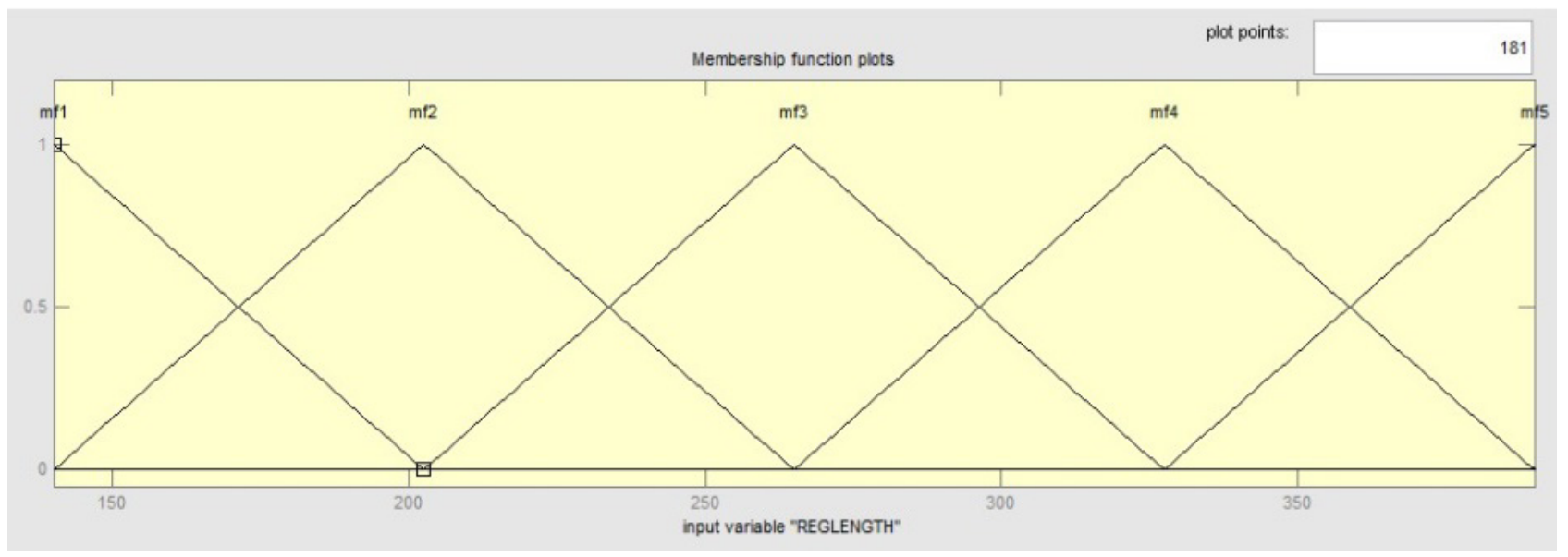

Figure 19. Membership functions for input variable regenerator diameter 


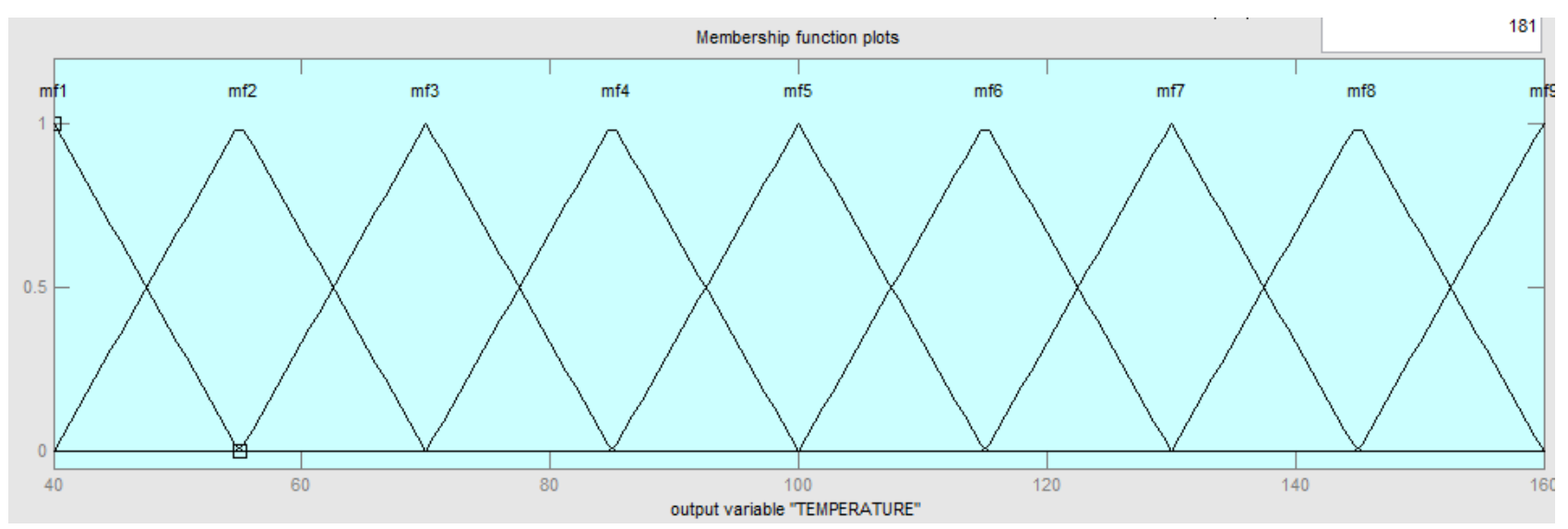

Figure 20. Membership functions for input variable regenerator length

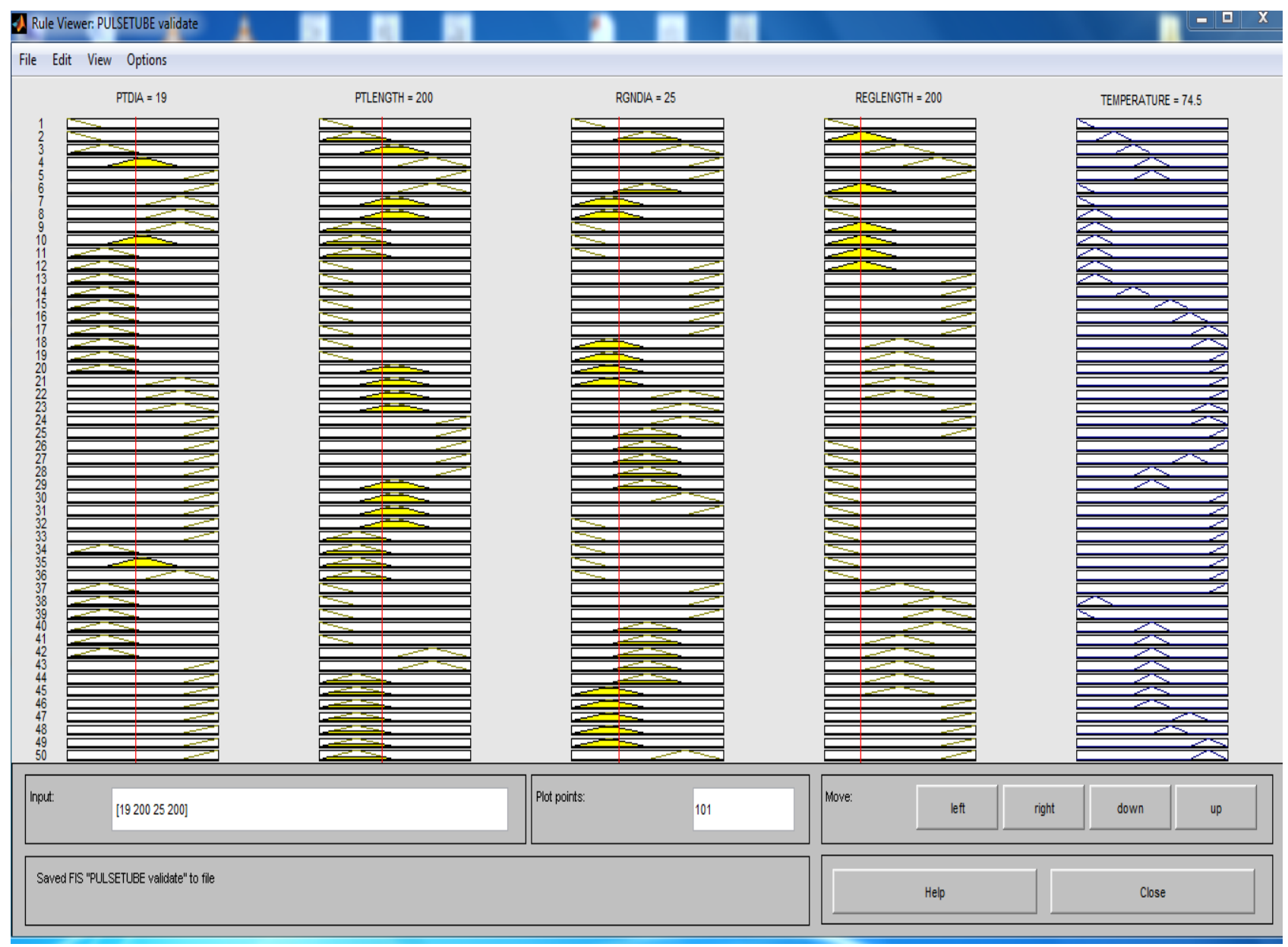

Figure 21. Rules of the fuzzy logic

\section{Conclusions}

A numerical approach is presented in this work to study the multi-dimensional flow characteristic of inertance type pulse tube refrigerator (PTR). The results obtained by the numerical analysis and previously published works have been compared. It can be concluded that the present numerical method provides a reasonably accurate estimation of responses. Therefore, it can be adopted to predict the responses before going for actual experiment to save both time and cost of experimentation. The pressure variation inside the inertance type pulse tube refrigerator plays a crucial role in the investigation. The results indicated that a porosity value of $(0.6)$ gives a better results. Therefore, the proposed model can be used for selecting ideal process states to improve the performance of PTR. Moreover, the oscillatory flow solid-fluid interactions are analysed with a realistic thermal non-equilibrium model for all porous zones. 
It is found a higher temperature at the cold heat end for thermal non-equilibrium model than that of thermally equilibrium model. This is due to the presence of Forchheimer term inside the porous medium. From the above investigation, it shows that the inlet fluid and solid matrix temperatures are the same at the regenerator exit , where the fluid temperature is about $(136 \mathrm{~K})$, while the solid temperature is more than $(144 \mathrm{~K})$. In addition, the heat transfer analysis of pulse tube refrigerator was modelled by using the fuzzy logic controller. This model was used on the basis of obtaining a relationship between input variables which are the diameter and length of pulse tube together with the regenerator , while the output variable is the cold end temperature .The rest parameters are considered constant during the numerical simulation. The values obtained from the fuzzy logic were found to be in a good agreement with the actual values. So, it can be concluded that the fuzzy logic is a reliable technique due to its high accuracy.

\section{Nomenclature}

\section{a piston displacement $(\mathrm{m})$}

a0 piston displacement amplitude (m)

Cp specific gas constant $(\mathrm{J} / \mathrm{kg}-\mathrm{K})$

$\mathrm{C}$ inertial resistance $\left(\mathrm{m}^{-1}\right)$

E total energy $\left(\mathrm{JKg}^{-1}\right)$

$\mathrm{h}$ enthalpy $(\mathrm{J} / \mathrm{kg})$

$\mathrm{j}$ superficial velocity $(\mathrm{m} / \mathrm{s})$

$\mathrm{k}$ thermal conductivity $(\mathrm{W} / \mathrm{m}-\mathrm{K})$

p pressure $\left(\mathrm{N} / \mathrm{m}^{2}\right)$

$\mathrm{T}$ temperature $(\mathrm{K})$

$\mathrm{t}$ time (s)

$\mathrm{v}$ velocity $(\mathrm{m} / \mathrm{s})$

$\mathrm{V}$ volume $\left(\mathrm{m}^{3}\right)$

$\mathrm{Sx}$, Sy momentum source terms $\left(\mathrm{Nm}^{-3}\right)$

\section{Greek Symbol}

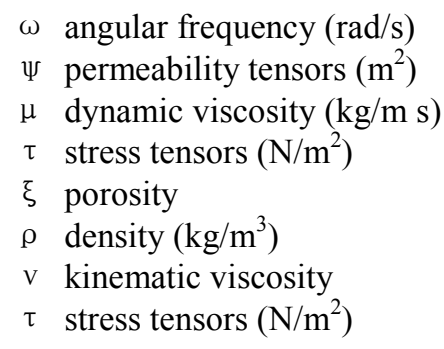

\section{Subscripts}

\section{S solid}

f fluid

$\mathrm{z}$ frequency

y radial coordinate

$\mathrm{x}$ axial coordinate

\section{REFERENCES}

[1] Gifford W., Longsworth R. Pulse-tube refrigeration. Trans ASME, J Eng.Ind (series B) 1964, $86: 264-268$.

[2] Mikulin E., Tarasov A., Shrebyonock M .Low-temperature expansion pulse tubes, Advances in Cryogenics Engineering 1984, 29: 629-637.

[3] Zhu S., Peiyi W., Zhonggi, Matsubara Y. Double inlet pulse tube refrigerator: an important improvement, Cryogenics 1990, 30: 514-520.

[4] Matsubara, Y., Gao, J.L. Multi-stage pulse tube refrigerator for temperature below 4K. Proceeding of 8th Cryocooler Conference, 1994: p. 345.

[5] Zhu, S. Active-buffer pulse tube refrigerator. Proceedings of 16th International Cryogenic Engineering Conference / International Cryogenics Materials Conference, 1996: p. 291.

[6] Wang, C. Experimental study of multi-bypass pulse-tube refrigerator. Cryogenics, 1995. 35, $9: 555-558$.

[7] Zhu, S., Kakimi Y. , Matsubara, Y. Investigation of active-b uffer pulse tube refrigerator. Cryogenics, 1997. 37 , 8: 461-471.

[8] Pan, H., Hofmann, A. , Oellrich, L. Single-stage 4-valve and active buffer pulse tube refrigerators. Cryogenics, 2001, 41, 4: 281-284.

[9] Chen, L., Zhang, Y., Luo, E., Li, T., Wei, X .CFD analysis of thermodynamic cycles in a pulse tube refrigerator, Cryogenics 2010, $50: 743-749$.

[10] Ashwin T., Narasimham G., Jacob S .CFD analysis of high frequency miniature pulse tube refrigerators for space applications with thermal non-equilibrium model , Cryogenics 2010, $30: 152-166$.

[11] Cha J., Ghiaasiaan S. Multi-dimensional flow effects in pulse tube refrigerators. Cryogenics 2006, 46: 658-665.

[12] Rout, S.K., et al. Numerical analysis of mixed convection through an internally finned tube. Advances in Mechanical Engineering 2012 (ID 918342) doi:10.1155/2012/918342.

[13] Zadeh, L. Fuzzy sets, Information and Control 1965, 8 , $3: 338-353$.

[14] Selimefendigil, F. and Öztop, H. Fuzzy-based estimation of mixed convection heat transfer in a square cavity in the presence of an adiabatic inclined fin. International Communications in Heat and Mass Transfer 2012, 39,10 : 1639-1646.

[15] Karami A. , et al., Fuzzy logic to predict the heat transfer in an air cooler equipped with different tube inserts. International Journal of Thermal Sciences, 2012, 53: 141-147.

[16] Wang, G., et al., Fuzzy estimation for temperature distribution of furnace inner surface. International Journal of Thermal Sciences, 2012, $51: 84-90$. 
[17] Şahin, A. Optimization of solar air collector using genetic algorithm and artificial bee colony algorithm, Heat and Mass Transfer 2012, $48,11: 1921-1928$.

[18] Juntaek, R., Dragojlovic, Z., Kaminski, D. Control of convergence in a computational fluid dynamics simulation using ANFIS. Fuzzy Systems, IEEE Transactions 2005 , 13, 1: 42-47.

[19] Mahmoud, M. , Ben-Nakhi, A. Neural networks analysis of free laminar convection heat transfer in a partitioned enclosure. Communications in Nonlinear Science and Numerical Simulation $2007,12,7: 1265-1276$.

[20] Xie, G. , Wang, Q. , Zeng, M. , Luo, L. Heat transfer analysis for shell-and-tube heat exchangers with experimental data by artificial neural networks approach, Applied Thermal Engineering 2007, 27, 5-6 :1096-1104.

[21] Varol, Y., Avci, E. , Koca, A. , Oztop, H. Prediction of flow fields and temperature distributions due to natural convection in a triangular enclosure using Adaptive-Network-Based Fuzzy Inference System (ANFIS) and Artificial Neural Network (ANN), International Communications in Heat and Mass Transfer 2007, 34, 7 : 887-896.

[22] Aminossadati, S., Kargar, A. , Ghasemi, B. Adaptive network-based fuzzy inference system analysis of mixed convection in a two-sided lid-driven cavity filled with a nanofluid. International Journal of Thermal Sciences 2012, $52: 102-111$.

[23] Liu, X. , Tao, W. , Zheng, P., He, Y., Wang, Q.Control of convergence in a computational fluid dynamic simulation using fuzzy logic, Sci. China Ser. E-Technol. Sci. 2002, 45 , $5: 495-502$.

[24] Diaz, G., et al., Dynamic prediction and control of heat exchangers using artificial neural networks. International Journal of Heat and Mass Transfer 2001, 44, 9 : 1671-1679.

[25] Dragojlovic, Z. , Kaminski, D. A fuzzy logic algorithm for acceleration of convergence in solving turbulent flow and heat transfer problems. Numerical Heat Transfer Part B: Fundamentals 2004, 46, 4 : 301-327.

[26] Islamoglu, Y., Kurt, A. Heat transfer analysis using ANNs with experimental data for air flowing in corrugated channels. International Journal of Heat and Mass Transfer 2004, 47 , 6-7: 1361-1365.

[27] Islamoglu, Y., A new approach for the prediction of the heat transfer rate of the wire- on -tube type heat exchanger- use of an artificial neural network model. Applied Thermal Engineering 2003 , 23 , 2: 243-249.Fluent 6.3 User's Guide, Fluent Inc.,http://www.fluentusers.com. 